\title{
Parents' talk and early literacy in preschool children
}

\author{
Asma Dabiri \\ dabiri_asma@yahoo.com \\ Shiraz University of Medical Sciences, Shiraz, Fars, Iran \\ School of Paramedical Sciences, Opposite Homa Hotel, Meshkinfam St., Shiraz, Iran. \\ P.O. Box: $71439-14693$
}

Received: December 11, 2017; $\quad$ Accepted: January 19, 2018; $\quad$ Published: March 2, 2018

\begin{abstract}
In this research, children's early understanding of the functions of print and parents' mediation, talk about the purpose of writing, and their elaborative reminiscing talk was investigated in Persian preschoolers. The study was a mixed-method type of research. Preschool children (seventeen girls and thirteen boys) and their mothers participated in the study. In order to obtain data, they were involved in a task game (a grocery-list task) obtained from the experts and they discussed a past event together. Analyses of the obtained data revealed that children with better notating skills had parents who provided more assistance when notating and used more elaborative talk, but did not talk more about the purpose of writing. The results suggested that in pre-school years, what parents did and said may play a role in children's symbolic, numeracy, and literacy development, although it did not relate to children's mastery of the conventions of print. Finding this continuity is important because it helps researchers revise and bridge theories about parenting and children's early literacy and numeracy and symbolic development.
\end{abstract}

Keywords: early literacy, prescholers, notating skills

How to cite this paper: Dabiri, A. (2018). Parents' talk and early literacy in preschool children. Journal on English as a Foreign Language, 8(1), 97-114 (doi: 10.23971/jefl.v8i1.725)

DOI: http://dx.doi.org/10.23971/ßefl.v8i1.725 
Children learn various written marks prior to learn reading and writing at school. Children acquire written marks that are idiosyncratic (e.g., scribbles) to iconic (e.g., drawings and tallies) to conventional (e.g., letters and numerals) (Levin \& Bus, 2003; Tolchinsky, 2007; Bus \& Neuman, 2014; Crosby, Rasinski, Padak \& Yilddrim, 2015; Goouch \& Lambirth, 2014). These written marks or external representations produced, read, and used in communicative or problem-solving contexts are called notations (Tolchinsky, 2007). By characterizing them as notations, it is aimed to include written marks representing information about objects, personal names, verbs, and number or quantity information.

Preschoolers' notating skills reflect how children develop an early understanding of the functions of print. Children must have some appreciation of the intentional nature of written marks: one intends to make a written mark in order to communicate and/or remember some information in order to produce, read, and use notations (DeLoache, 2000; Namy, 2005). Children who produce, read, and use notations must also have some appreciation of the referential nature of written marks: a written mark refers to something other than itself (e.g., an idea) by virtue of perceptual similarity (e.g., a picture of a boat refers to a boat), or conventionality (e.g., $\mathrm{M}$ refers to the sound $/ \mathrm{m}$ ) (Lonigam, Farvar, Nakamoto, \& Eppe, 2013).

A number of studies on symbolic development have examined children's understanding of the intentional and referential nature of various symbols, including gestures (Namy, Campbell, \& Tomasello, 2004), drawings and pictures (Preissler \& Carey, 2004), simple maps and 3D-models (Liben \& Myers, 2007), printed words and videos (Bialystok \& Martin, 2003). It can be concluded two roles, the producer and the user of a symbol are essential in studying children's role-taking in a communicative and/or problem-solving situation (Namy, 2005; Tomasello, 2007). For example, children's production and/or use of pictures and gestures have been investigated in the context of communicating some information to others (Namy et al., 2004). In notating skills, Lonigam et al. (2013) examined preschoolers' ability to produce and use numeric notations in a problem solving situation. They found that preschoolers produced an array of numeric notations, but could only use them functionally to solve a problem when they were highly conventionalized (i.e., numerals).

Studies on emergent writing (Bus \& Neuman, 2014; Tolchinsky, 2007; and early numeracy (Seo \& Ginsburg, 2003; Aunio, Aubrey, Godfrey, Pan, \& Liu, 2008) have usually focused on mastering the conventions of print (whether letters or numerals), rather than on children's ability to understand the functions of print. Mastering conventions of print includes knowing the name 
of letters and numbers and writing them, knowing how to articulate letters, and print concepts.

Generally, few studies have been done on how children produce, read, and use written marks, even when they are not conventional, for purposes such as communicating or remembering information about objects and quantities. In standardized tests of emergent writing, children are asked to write some information that is dictated to them, but writing is not presented to children as a functional tool in a meaningful context. Standardized tests of early numeracy typically focus on skills such as counting objects, matching numerals with the quantities they represent, basic arithmetic abilities (addition and subtraction), and logical principles (e.g., conservation). It is not obvious to young children that writing (whether letters or numerals) is a communicative tool (Tolchinsky, 2003; Bus \& Neuman, 2014; Lonigan, Goouch \& Lambirth, 2016; Allen \& Phillips, 2017) or that it can serve a functional purpose in real life, such as a mnemonic aid.

Thus, more research is needed in order to understand how children come to appreciate the functions of print and to identify the factors that may be involved in the development of this ability. So, it is worth studying to investigate children's appreciation of the intentional and referential nature of writing, that is, early understanding of the functions of print, by assessing their ability to assume both the role of the producer (encoder) and the user (decoder) of their own notations to solve a problem. Based on these concerns, this study examined parents' talk to preschool children (Persian preschoolers) and to a different aspect of print development, notating skills, which reflect an understanding of the intentional and referential nature of writing.

Talking about the role of parents' talk, Braswell and Callanan (2003) reported mothers who talked about the distinctive features of drawings while playing a collaborative drawing game had children who modified their drawings to make them more sophisticated and understandable to their mothers. Also, mothers who provided comments and helped interpreting and using a pictorial plan to construct a toy had children with greater anticipatory use of plans in a post-test task (Gauvain, de la Ossa, \& Hurtado- Ortiz, 2001). In a math task of ratios and proportions, children benefited more from mothers who talked about the specific mathematical content involved in the task (i.e., maternal statements about ratios or proportions) (Pan, Gauvain, Liu, \& Cheng, 2006). The mentioned studies have demonstrated parents' talk in interaction with their children influenced children's understanding of external representations. These studies suggested the content of parental talk might be linked to the development of children's early understanding of the functions of print.

Journal on English as a Foreign Language, 8(1), 97-114

Copyright (C) 2018 by JEFL, p-ISSN 2088-1657; e-ISSN 2502-6615 
A further set of studies has indicated that parents' talk during decontextualized conversations, those that are focused on temporally displaced events rather than ongoing events, is related to children's print skills. One example of a highly decontextualized conversation is when parents and children discuss past events together (Fivush, Haden, \& Reese, 2006; Bus \& Neuman, 2014). Mothers who use a highly elaborative style in decontextualized conversations have children with more advanced print concepts (Sparks \& Reese, 2009; Goouch \& Lambith, 2016). Elaborative reminiscing is a talk style characterized by a greater use of open-ended questions (e.g., what, where, who, why) and evaluative feedback that invites the child to provide more information about the past event and to add more pieces of information to construct a story in rich detail (Goouch \& Lambirth, 2016).

From the review of the related literature on early literacy in children, it can be concluded that the structure revealing the link between parents' elaborative reminiscing style and children's print concepts has not been well examined (Levin \& Bus, 2003; Tolchinsky, 2003; Bus \& Neuman, 2014; Goouch \& Lambirth, 2014; Crosby, Rasinski, Padak, \& Yilddrim, 2015). Fivush et al. (2006) suggested that an elaborative reminiscing style required children to distance cognitively from their immediate experience and work on information that was not perceptually available, for example, by drawing causal relationships, making inferences, and predicting different potential outcomes. Presumably, this cognitive distancing is similar to the cognitive demands used when interpreting print and comprehending a written story. Thus, mothers who use an elaborative reminiscing style may be helping their children's abstract thinking skills, which then aid children in acquiring print concepts. From this perspective, elaborative reminiscing might benefit a range of cognitive, linguistics and socio-cognitive skills that involve distancing or perspective-taking, such as theory of mind, emotion understanding, memory and an understanding of print (Fivush et al., 2006; Wareham \& Salmon, 2006). Lonigan et al. (2013) found that the link between children's print skills and adults' talk during decontextualized conversations was not specific to parents. Preschool teachers' decontextualized talk was also related to kindergarten children's print concepts, letter recognition, and writing and story concepts.

The link between children's print concepts and maternal elaborative reminiscing style has only been found in kindergarten children and is limited to children's appreciation of one specific aspect of print: its conventionality (Leyva, Reese \& Wiser, 2012; Lonigan, Allan \& Phillips, 2017). Hence, based on these concerns, the posed research question in this study was: Is preschool children's early understanding of the functions of print related to parents' 
mediation, talk about the purpose of writing, and their elaborative reminiscing talk?

\section{METHOD}

The study was in the form of a mixed method research, combining quantitative and qualitative approaches in different phases of the study. In the following, briefly, the research design and analysis will be explained. For children's notating skills: A composite measure of children's notating skills in the trial of the grocery-list task was formed. This composite was based on their individual scores in encoding, decoding, and checking the list. Scores on encode the list were based on a 6-point scale which ranged from idiosyncratic (e.g., scribbles), to iconic (recognizable pictures, tallies) to conventional (e.g., Arabic numbers, letters). For parents' notating mediation: a 5-point scale was used to assess the parent's willingness to allow the child to make her or his own decisions (e.g., choose a strategy to notate), while offering guidance and feedback during the grocery-list task (i.e., if the child chose to make scribbles, the parent posed questions that helped the child chose better notating strategies, such as drawing pictures or color code scribbles). For parents' talk about writing: parents' utterances during the grocery-list task were scored based on whether it included explanations, comments, or questions about the goal of writing and/or required the child to connect writing with the goal of retrieving specific information later on. For, parents' elaborative talk: Parents' elaborative reminiscing talk was assessed using Haden's coding scheme.

\section{Participants}

The participants were thirty preschool children (seventeen girls and thirteen boys) and their mothers; they were all Persian native speakers. Ninetytwo percent of mothers had a bachelor's (or higher) degree and eight percent had an associate degree or a high-school diploma. The children ranged in age from 46 to 63 months. None of the children was able to read or write independently at the time of the study according to parents' report. Participants were selected from three daycare centers located in Shiraz, Iran. All parents reported that the primary language spoken at home was Persian.

\section{Instruments}

Instruments to gather data were obtained from (Leyva, Reese \& Wiser, 2012). A game named, 'grocery-list' played solo and joint was used. To check the frequency with which they engaged with their children in book reading and teaching letters and numbers during a typical week, a questionnaire using a 5point scale from never (1) to very often (5) was used. They also reported 
whether their children observed the parents making grocery lists, whether parents regularly made grocery lists, and whether children had helped them at least once to make grocery lists. Parents filled out a short demographic form about their ethnicity and level of education.

\section{Data Collection Procedures}

The first 'game' was the solo trial of the grocery-list task. While the child was completing the task, the parent filled out a questionnaire on home literacy practices and demographic information in a different room. Thus, the parent was not aware of the kind of tasks the child had completed with the researcher. Then each parent and child were reunited and asked to play a new grocery- list task with a different 'grocery store' (joint trial) and to talk about something that they did together in the past. Half of the parents played the grocery-list task first and then talked about a past event, and half completed the tasks in the opposite order. The total duration of the session was around 45-50 minutes. Children were given a small gift for their participation at the end of the session. They were videotaped during the solo trial of the grocery-list task and parents and children were videotaped during the joint trial of the grocery-list task and the past-event conversations. Home literacy practices questionnaire and demographic form was also used to gather data on whether there existed literacy practices at home or not and to obtain information about demographic facts.

\section{Solo Trial of the Grocery-list Task}

The materials for the grocery-list task were: a small basket, a piece of paper, a box of markers (7 different colors) and the 'grocery store,' which was a plastic opaque box with a lid and four compartments. The store had 20 fruit props (5 of each kind): apples, pears, bananas, and oranges. A small table with two chairs for the child and the researcher to sit was called 'home.' The researcher announced that they were going to pretend to go grocery shopping. The child was then shown the 'grocery store' and asked to identify each kind of fruit in it. All children easily recognized the fruits. Then the researcher put the lid on the box and placed the 'grocery store' away from 'home.' The researcher told the child that she had too many things to buy at the store and was afraid she might forget something. She then asked the child: 'What can we do to remember all the things we need?' If the child thought about producing a list (or writing it up) the researcher said: 'Good idea! What is a grocery list?' If the child did not think of producing a list, the researcher said: 'How about we make a grocery list? What is a grocery list?' The child's knowledge about grocery lists was used as a control variable. Regardless of the child's answer, the 
researcher stated what a grocery list was: 'A grocery list is when you put down on paper all the things that you need to buy before you go grocery shopping, so you don't forget them.'

The child was asked to make a list with the following items: 3 apples, 5 pears, 2 bananas, and 4 oranges. The researcher provided only general positive feedback (e.g., 'Nice job'), but no specific instruction or feedback on the child's performance was provided. The child was not corrected if she or he made any errors. If the child mentioned that she or he did not know how to write/read yet, the researcher said: 'That's OK. Just put down something on paper so we remember this is what we need at the store.' Next, the researcher announced that the store was closed and would open in 15 minutes. By introducing a standard 15-minute delay it was insured that any decoding was not simply the memory of a momentary intention when initially making the mark. The researcher asked the child to read back the list before going grocery shopping; no help was provided. The researcher and the child then walked to the 'grocery store' with the basket and the list, and grabbed the fruit they needed. The researcher, however, deliberately 'forgot' to buy one pear. Because she never counted the fruit aloud for the child and always handed more than one fruit to the child, and no child realized that there was one pear missing. Then the researcher and the child went back 'home.' The researcher looked at the basket and announced that they might have forgotten something at the store and asked the child: 'What can we do to make sure we bought everything we needed?' If the child did not think about checking the list, the researcher suggested the child to do so. The researcher never assisted the child in producing, decoding, or checking the list.

\section{Joint Trial of the Grocery-list Task}

The materials were the same as the solo trial, except for the grocery store, which in this case had on display only 10 fruits ( 5 oranges and 5 sour oranges). These fruits were chosen because their similar shape and color presented a challenge for children to encode and decode, and thus, elicited parents' mediation in producing the list.

Parents were told that the child had previously played a game related to grocery shopping with the researcher. They were also told that this was a new game with a different pretend store and different fruits than the ones the child had previously seen with the researcher. Instructions to parents were given in written form, so that the child would not be aware of them. The researcher insured parents understood the three steps: (1) making the list (5 oranges and 4 sour oranges), (2) going to the store and 'forgetting' one orange, and (3) checking the list. Parents were encouraged to let their children be the 'grocery- 
list maker,' but to provide help if necessary; they were not explicitly asked to help their children decode the grocery list after they produced it. Parents were not instructed to talk about the purpose of writing as a tool to remember or convey information.

\section{Parent-child Past-event Conversation}

Parents were asked to think about a one-time special past event that they experienced with their children (e.g., going to the park), and to talk about it with their children as they normally would. The researcher was not present during the conversation to allow the children and parents to feel comfortable.

\section{Home Literacy Practices Questionnaire and Demographic Form}

Parents filled out home literacy practices questionnaire and a short demographic form about their ethnicity and level of education.

\section{Data Analysis}

\section{Children's Notating Skills}

Children's scores in encoding, decoding, and checking the list were estimated. Scores of encoding the grocery list were based on a 6-point scale adapted from Tolchinsky (2007) which ranged from idiosyncratic (e.g., scribbles), to iconic (recognizable pictures, tallies) to conventional (e.g., numbers, letters). Each notation (or group of notations) was estimated representing information about a type of fruit and then the scores were averaged across the four types of fruits to encode (i.e., apples, pears, bananas, oranges). The same procedure was followed for information about quantity of fruit. First each notation representing quantity of fruit was scored and then it was averaged across the four quantities (i.e., 3 [apples], 5 [pears], 2 [bananas], 4 [oranges]). Average scores on information about type and quantity of fruit were then averaged to obtain a final score. Scores of decoding the grocery list were based on the average total number of pieces of information about type and quantity of fruit correctly decoded (ranging from 0 to 4 ). The researcher coded this information immediately as it occurred as the child decoded her or his grocery list, giving a 1 or 0 for each piece of information about type of fruit and for each piece of information about quantity of fruit depending on whether it was correctly decoded. Scores were summed across the four pieces of information about type of fruit information; the same procedure was followed for information about quantity. The final score of decoding was the average score obtained on information about type and quantity of fruit. Scores of checking the list were based on the total number of information about type and quantity of fruit correctly checked (ranging from 0 to 4 ). 


\section{Parents' Notating Mediation}

A 5-point scale was adapted from Aram and Levin (2001) to assess the parent's willingness to allow the child to make her or his own decisions (e.g., choose a strategy to notate), while offering guidance and feedback during the grocery-list task (i.e., if the child chose to make scribbles, the parent posed questions that helped the child choose better notating strategies, such as drawing pictures or color code scribbles). Anchor points in this global scale were: (1) a list written by the parent with no help from the child, or done by the child without any parental feedback and/or support; (3) both parent and child contributed to the list, with the child playing a secondary role; (5) a list was encoded entirely by child, with the parent providing feedback and/or support throughout the process. It is important to note that some level of parental mediation was necessary to produce a useful list because none of the children was able to write independently and producing differentiated drawings of fruits was challenging for preschoolers.

\section{Parents' Talk about Writing}

Parents' utterances during the grocery-list task were scored based on whether it included explanations, comments, or questions about the goal of writing and/or required the child to connect writing with the goal of retrieving specific information later on. Examples of these type of comments are, 'Can you write 4 [oranges] so that we remember how many we need to get?' or 'If we don't write what we need, we will forget it.' parents' content of talk was recorded in two scores: a dichotomous and a continuous score. The dichotomous score (TALK) indicated the presence/absence of talk about writing. Parents were given credit (score of 1) if they asked at least one question, or introduced at least one comment or explanation about the goal of writing during the grocery-list task. A continuous score (WRITING) was based on the proportion of total utterances coded that included talk about writing. For example, if the parent produced 12 utterances during the grocery-list task and introduced comments or explanations or asked questions in 2 of them, the continuous score was $2 / 12=.17$.

\section{Parents' Elaborative Talk}

Parents' elaborative reminiscing talk was assessed using Haden's coding scheme. In this coding scheme, parents' utterances were coded as elaborative in the past-event conversation if they contained new information, or repetitive if they contained no new information, and then sub-coded each elaborative and repetitive utterance as open-ended questions (e.g., 'Where did we go for your birthday?'), yes/no questions (e.g., 'Did you play in the park?'), or statements 
(e.g., 'They are called poems, poems about each rabbit'). Evaluations (child says 'Zoo' and mother says 'That's right'), place holders (e.g., 'that's all!'), fill-in-theblank questions (e.g., 'and then we played on the ...'), and off-task utterances were also coded. The final score was based on the proportion of open-ended elaborative questions out of the total number of on-task coded utterances; proportions to account for differences in length of conversation were posed.

\section{Reliability}

To estimate inter-and intra-coder reliability, ten pages of the coded data were randomly chosen. To gain the intra-coder reliability, they were coded again by the researcher ten days after the first coding and the intra-coder reliability was found to be 0.98 . For the inter-coder reliability, one rater not participating in the study coded them and the inter-coder reliability was found to be 0.88 .

\section{Home Literacy Practices Questionnaire}

Parents reported their highest level of education using a 4-point scale: $1=$ 'high-school,' 2 = 'two-year college,' 3 = 'bachelor's degree,' 4 = 'post-graduate degree.' Each item was examined to determine the number and proportion of responses.

\section{FINDINGS}

All children completed the solo trial of the grocery-list task. Thirty percent of the children in the sample made some kind of comment about 'not knowing how to write or read/not knowing the alphabet'. No statistically significant differences in notating skills or conventional print skills were found between the group of children who made this kind of comment and the group that did not (t-tests, all ps >.10). T-tests were conducted and no differences were found by gender on children's and parents' measures (all ps > .10); thus child gender was also eliminated from subsequent analyses.

Parents' notating mediation, talk about writing, and elaborative reminiscing talk were not inter-correlated ( $r$ s ranged from -.01 to -.15 , all $p \mathrm{~s}>$ .10). This indicates that parents' measures (predictors) used in this study were independent. Analyses also showed that children's notating skills were positively related to their conventional skills $(r=.49, p<.001)$ and remained significantly associated to them even after accounting for child age $(\mathrm{p} r=.34, p<$ .001). Children's conventional skills were not related to talk about writing ( $\mathrm{p} r=$ $.17, p>.10$ ), or elaborative style ( $p r=-.11, p>.10$ ) after controlling for child age. See Table 1 for descriptive statistics for the outcome (children's notating skills), predictors (parents' measures), and covariates (home literacy environment, and 
demographic characteristics).

Table 1. Descriptive Statistics on Children's and Parents' Measures, and Covariates

\begin{tabular}{|l|l|l|}
\hline & $M(\mathrm{SD})$ & Range \\
\hline Children's measure (outcome) & & \\
\hline Notating skills & $2.5(1.75)$ & $0.66-5.85$ \\
\hline Parents' measures (predictors) & & \\
\hline Notating mediation & $3.1(1.6)$ & $1-6$ \\
\hline $\begin{array}{l}\text { Talk about writing (proportion of total } \\
\text { utterances) }\end{array}$ & $0.13(0.18)$ & $0.11-0.51$ \\
\hline $\begin{array}{l}\text { Elaborative talk (proportion of total } \\
\text { utterances) }\end{array}$ & $0.43(.091)$ & $0.32-0.70$ \\
\hline Covariates: & & $43-67$ \\
\hline Child age (months) & $51.4(7.1)$ & $1-5$ \\
\hline $\begin{array}{l}\text { Child knowledge of grocery lists } \\
\text { Frequency parents read books }\end{array}$ & $4.37(1.65)$ & $1-5$ \\
\hline $\begin{array}{l}\text { Frequency parents teach } \\
\text { letters/numbers(average) }\end{array}$ & $3.11(1.14)$ & $1-5$ \\
\hline
\end{tabular}

To address the research question, using multiple regression analysis, in model 1 the main effects of the covariates were included (child age, child knowledge of grocery lists, home literacy practices, and parental education) on the outcome. Child age was positively and statistically related to children's notating skills. In model 2 the main effects of the predictors were added, i.e., parent measures. Parents' notating mediation and elaborative talk were positive and significantly related to children's notating skills even after controlling for the effects of all covariates. In addition, the effects of child age remained statistically significant, while the negative effect of frequency of teaching letters and numbers was no longer present. Parental education proved not associated with children's notating skills. The goodness of fit of a full model (Model 2 which includes all predictors and covariates and accounts for $64 \%$ of the outcome variance) was contrasted to that of a reduced model (including only the effects of parents' mediation and elaborative style, child age, and accounting for $57 \%$ of the outcome variance). Model 2 's goodness of fit was not any better than that of the reduced model $(F(7,47)=1.11, p>.10)$. Hence, the joint effects of parents' talk about writing and several covariates on children's notating skills were dropped. 
In subsequent models' interaction effects of predictors and covariates were tested and it was found that these were not statistically significant. Thus, Model 3 is the 'final reduced model' containing the significant main effects of parents' mediation and elaborative style, and child age. In Table 2, multiple regression models are presented. See Appendix for a detailed explanation of the model fitted in the regression analysis.

It was concluded that children with parents who provided higher levels of notating mediation and those who were more elaborative when reminiscing, had better notating skills in the grocery-list task. Parents' mediation and elaboration accounted for $25 \%$ of the variance in children's notating skills. Child age was also associated with better notating skills. These covariates accounted for $32 \%$ of the variance in children's notating skills.

Table 2. Regression Models Describing the Relation between Children's Notating Skills and Parents' Measures, Controlling for Selected Covariates

Parameter estimates

\begin{tabular}{|l|c|c|c|c|}
\hline & Parameter & Model 1 & Model 2 & Model 3 \\
\hline Intercept & $\beta 0$ & $-7.29^{* * *}$ & $-10.43^{* * *}$ & $-7.49^{* * *}$ \\
\hline MEDIATION & $\beta 1$ & & $0.26^{*}$ & $0.29^{*}$ \\
\hline TALK $\times$ WRITING & $\beta 2$ & & -1.04 & \\
\hline TALK & $\beta 3$ & & 0.59 & \\
\hline ELABORATIVE & $\beta 4$ & & $7.93^{*}$ & $6.75^{*}$ \\
\hline Child age & & $0.12^{*}$ & $0.13^{* * *}$ & $0.12^{* *}$ \\
\hline Parental education & & -0.36 & -0.42 & \\
\hline Goodness of fit statistics & & \multicolumn{5}{|l}{} \\
\hline$R^{2}$ & & .50 & .64 & .57 \\
\hline SS error & & 76.60 & 54.60 & 64.84 \\
\hline d.f. error & & 51 & 47 & 55 \\
\hline
\end{tabular}

$+p<.10,{ }^{*} p<.05,{ }^{* *} p<.01,{ }^{* * *} p<.001$

\section{DISCUSSION}

This research examined whether and how parents played a role in the development of children's notating skills, that was, their ability to encode, decode, and check information using written marks for problem-solving, which reflected their early understanding of the functions of print. Three aspects of parent-child interaction: parents' notating mediation, the presence and amount of parents' talk about the purpose of writing in a grocery-list task, and

Journal on English as a Foreign Language, 8(1), 97-114

Copyright (C) 2018 by JEFL, p-ISSN 2088-1657; e-ISSN 2502-6615 
their decontextualized conversation in the form of elaborative reminiscing with their children were assessed. These measures of parent-child interaction were not inter-correlated. Thus, parents who provided more notating mediation in the grocery-list task were not necessarily talking more about the purpose of writing or using more elaborative talk in decontextualized conversations with their children. This finding is consistent with prior research showing independence of parents' level of autonomy support from their reminiscing talk and other measures of parent-child interaction (Fivush et al., 2006; Leyva et al., 2012; Bus \& Neuman, 2014).

Children who were superior at notating information using written marks in the grocery- list task had parents who provided more high-quality assistance when children produced written marks. Specifically, parents of children with better notating skills were more likely to mediate in an autonomy-supportive manner by allowing or encouraging children to find ways to encode the information. This finding supports previous research indicating the positive link between parents who encourage and support the child's interests, rather than their own, and children's task performance (Assor, Kaplan, \& Roth, 2002; Leyva et al., 2012; Crosby et al., 2015; Indriati, 2016).

Parents' elaborative reminiscing was also positively and uniquely related to children's notating skills, reflecting an understanding of the functions of print. Parents who used a higher proportion of open-ended questions adding new pieces of information during a decontextualized conversation had children with better notating skills in the grocery-list task. This is an important finding because it extends prior research in two ways: (1) by establishing a link between parents' elaborative reminiscing and children's print skills at a younger age than demonstrated previously (Fivush et al., 2006; Goouch \& Lambirth, 2016); and (2) by extending this link beyond children's conventional print skills to their notation skills reflecting their understanding of the functions of print. Parents who are more elaborative in a decontextualized conversation have preschool children who are more advanced at appreciating print as a communicative tool: written marks are intended to stand for ideas. Parents' elaborative talk may help children connect their representation of an event (their memory) with the spoken words about the event (the reminiscing conversation) (Leyva et al., 2008; Leyva et al., 2012; Lonigam, Farvar, Nakamoto, \& Eppe, 2013).

The existence and amount of parents' talk about the purpose of writing was not related to children's notating skills. It is important to note that parents were not instructed to engage in this kind of talk, but that most of them (70\%) spontaneously discussed this topic at least once with their children during the grocery-list task. There are several ways to explain the lack of association 
between parents' talk about the purpose of writing and children's notating skills. First, although this kind of talk was present in most parent- child interactions, the amount of talk was relatively low, with most parents only mentioning the purpose of writing once during the period of the grocery-list task. It is possible that parents did not intensively engage in this talk because they assumed that their children already had this knowledge (i.e., they already understood the intentional nature of making a grocery list). Thus, they tailored their verbal and nonverbal scaffolding to other aspects of writing, for example, the shape or the sound of letters. It is possible that the preschoolers whose parents spontaneously talk about the purpose of writing would later on display more sophisticated notating skills or even print skills at school.

This study contributed to the related literature on early literacy and symbolic development in at least two important ways. First, the merits of the grocery-list task proposed by Leyva et al. (2012) were supported by the evidence gathered in this study. Children's performance in the grocery-list task, i.e., notating skills, was related to their conventional skills (letter/word and number recognition and print concepts). Parents' notating mediation and elaborative talk were related to notating skills even after accounting for their conventional skills, age and other covariates. However, children's conventional skills were not yet related to any of parents' measures. These findings suggest that the grocery-list task was a valid task to assess early literacy and symbolic development. It also showed that by examining children's notating skills a separate ability was tapped, early understanding of the functions of print, which was different from knowledge about the conventions of print. Second, this study contributed to the larger literature by extending the links between parents' printing mediation and reminiscing style and children's writing, numeracy, and reading skills to the preschool years.

\section{CONCLUSION}

This issue was investigated whether preschool children's early understanding of the functions of print was related to parents' mediation, talk about the purpose of writing, and their elaborative reminiscing talk or not. Children developed written marks that were idiosyncratic (e.g., scribbles) to iconic (e.g., drawings and tallies) to conventional (e.g., letters and Arabic numerals). These written marks or external representations produced, read, and used in communicative or problem-solving contexts were referred as notations (Tolchinsky, 2007). The research question which was posed in the study was: "Is preschool children's early understanding of the functions of print related to parents' mediation, talk about the purpose of writing, and their elaborative reminiscing talk?

Journal on English as a Foreign Language, 8(1), 97-114

Copyright (C) 2018 by JEFL, p-ISSN 2088-1657; e-ISSN 2502-6615 
Taking into account the research question of the present study, parents who provided higher levels of notating mediation and those who were more elaborative when reminiscing had better notating skills in the grocery-list task. Parents' mediation and elaboration accounted for $25 \%$ of the variance in children's notating skills. Child age was also associated with better notating skills. These covariates accounted for $32 \%$ of the variance in children's notating skills. Taken together, these findings indicated that two aspects of parent-child interaction are related to children's notating skills in the grocery-list task: parents' notating mediation and their decontextualized conversation in the form of elaborative reminiscing talk. These associations were statistically significant even after accounting for important covariates including child age, and parental education.

Prior research (Aram \& Levin, 2001, 2004, 2009) has focused on parents' assistance and reminiscing style in relation to kindergarten and older children's literacy skills. Other research has studied parental mediation (i.e., strategies and instructional techniques) during the preschool years, but has not focused on assistance in representing quantities or objects in written form (Benigno \& Ellis, 2004; Bjorklund et al., 2004; Pan et al., 2006). This study examined the role of parents' mediation, talk about writing, and reminiscing style in relation to preschool children's understanding of the functions of print. Parents' notating mediation and reminiscing style were related to children's early understanding of the functions of print, but not yet to their conventional skills. It suggested that in pre-school years, what parents do and say may play a role in children's symbolic, numeracy, and literacy development, although it does not yet relate to children's mastery of the conventions of print. Finding this continuity is important because it helps researchers revise and bridge theories about parenting and children's early literacy and numeracy and symbolic development.

\section{REFERENCES}

Aram, D., \& Levin, I. (2001). Mother-child joint writing in low SES: Socio-cultural factors, maternal mediation, and emergent literacy. Cognitive Development, 16, 831-852.

Assor, A., Kaplan, H., \& Roth, G. (2002). Choice is good, but relevance is excellent: Autonomy- enhancing and suppressing teacher behaviors predicting students' engagement in school- work. British Journal of Educational Psychology, 72, 261-278.

Aunio, P., Aubrey, C., Godfrey, R., Pan, Y., \& Liu, Y. (2008). Children's early numeracy in Eng- land, Finland and People's Republic of China. International Journal of Early Years Education, 16, 203-221. 
Bialystok, E., \& Martin, M. M. (2003). Notation to symbol: Development in children's under- standing of print. Journal of Experimental Child Psychology, 86, 223-243.

Braswell, G. S., \& Callanan, M. A. (2003). Learning to draw recognizable graphic representations during mother-child interactions. Merrill-Palmer Quarterly, 49, 471-494.

Bus, A. G., \& Neuman, S. B. (2014). Multimedia and literacy development: Improving achievement for young learners. London, England: Routledge.

Crosby, S.A., Rasinski, T., Padak, N., \& Yiddrim, K. (2015). A 3-year study of a school-based parental involvement program in early literacy. The Journal of Educational Research, 108, 165-172.

DeLoache, J. S. (2000). Dual representation and young children's use of scale models. Child Development, 71, 329-338.

Fivush, R., Haden, C. A., \& Reese, E. (2006). Elaborating on elaborations: Role of maternal reminiscing style in cognitive and socio-emotional development. Child Development, 77, 1568-1588.

Gauvain, M., de la Ossa, J., \& Hurtado-Ortiz, M. T. (2001). Parental guidance as children learn to use cultural tools: The case of pictorial plans. Cognitive Development, 16, 551-575.

Goouch, K., \& Lambirth, A. (2016). Teaching early reading and phonics: Creative approaches to early literacy. California, United States: Sage.

Indriati, I. (2016). Parents' involvement in supporting their children learn English. Journal on English as a Foreign Language, 6(2), 145- 170.

Leyva, D., Reese, E., \& Wiser, M. (2012). Early understanding of the functions of print: Parent-child interaction and preschoolers' notating skills. First language, 32(3), 301-323.

Leyva, D., Reese, E., Grolnick, W., \& Price, C. (2008). Elaboration and autonomy support in low-income mothers' reminiscing: Links to children's autobiographical narratives. Journal of Cognition and Development, 9, 363-389.

Liben, L. L., \& Myers, L. J. (2007). Developmental changes in children's understanding of maps: What, when, and how? In J. M. Plumert (Ed.), The emerging spatial mind (pp. 193-218). New York: Oxford University Press.

Lonigan, C. J., Allan, D. M., \& Phillips, B. M. (2017). Examining the predictive relations between two aspects of self-regulation and growth in preschool children's early literacy skills. Developmental Psychology, 53(1), 63-76.

Lonigan, C. J., Farver, J. M., Nakamoto, J., \& Eppe, S. (2013). Developmental trajectories of preschool early literacy skills: A comparison of languageminority and monolingual-English children. Developmental Psychology, 
49(10), 1943-1957.

Namy, L. L. (2005). Symbol use and symbolic representation: Developmental and comparative perspectives. Mahwah, NJ: Lawrence Erlbaum.

Namy, L. L., Campbell, A. L., \& Tomasello, M. (2004). The changing role of iconicity in non-verbal symbol learning: A U-shaped trajectory in the acquisition of arbitrary gestures. Journal of Cognition and Development, 1, 37-57.

Pan, Y., Gauvain, M., Liu, Z., \& Cheng, L. (2006). American and Chinese parental involvement in young children's mathematics learning. Cognitive Development, 21, 17-35.

Preissler, M. A., \& Carey, S. (2004). Do both pictures and words function as symbols for 18- and 24-month-old children? Journal of Cognition $\mathcal{E}$ Development, 5, 182-212.

Seo, K. H., \& Ginsburg, H. P. (2003). What is developmentally appropriate in early childhood mathematics education? Lessons from new research. In D. H. Clements, J. Sarama, \& A. M. DiBiase (Eds.), Engaging young children in mathematics: Standards for early childhood mathematicseducation (pp. 91104). Mahwah, NJ: Lawrence Erlbaum.

Tolchinsky, L. (2007). The multiple functions of external representations: Introduction. In E. Teubal, J. Dockrell, \& L. Tolchinsky (Eds.), Notational knowledge: Developmental and historical perspectives (pp. 1-10). Rotterdam: Sense Publishers.

Tomasello, M. (2007). Cooperation and communication in the second year of life. Child Develop ment Perspectives, 1, 8-12.

\section{Author's Brief CV}

Asma Dabiri, Ph.D. in Teaching English as a Foreign Language (TEFL) is a university lecturer in English (in 2016 to date as lecturer in English at Shiraz University of Medical Sciences, Shiraz, Fars, Iran, and in 2008 to 2016 as lecturer in English at the University of Applied Science and Technology (UAST), Shiraz, Fars, Iran. 


\section{Appendix}

The following model was fitted:

NOTATINGi $=\beta 0 \quad+\beta 1 M E D I A T I O N i+\beta 2$ TALKi $+\beta 3$ TALK $x$ WRITINGi $+\beta$ ELABORATIVE $+\gamma^{\prime} \mathrm{Z}+\varepsilon$

where NOTATING represents the sophistication of the notating skills of a child $i$ in the solo trial of the grocery-list task. Parameter $\beta 0$ is an intercept, $\beta 1$ represents the impact of the presence of parents' mediation in the joint trial of the grocery-list task (MEDIATION), $\beta 2$ is the effect of the presence of parents' talk about writing (TALK), $\beta 3$ is the effect of the amount of parents' talk about writing in the joint trial of the grocery-list task (TALK $\times$ WRITING), $\beta 4$ is the effect of parents' elaborative talk in a past-event conversation (ELABORATIVE), and $\gamma$ represents the effects of a vector of controls on the outcome. If estimates of the parameters $\beta 1, \beta 2$, and $\beta 3$ are positive and statistically significant then it is known that children who have better notating skills have parents who use more notating mediation, talk about writing (measured by presence and amount), and elaborative talk. Notice that the model contains the main effects of predictor TALK and the two-way interaction of predictors TALK and WRITING but not the main effect of predictor WRITING. This specification is adopted to account for the fact that parents who did not talk (TALK $=0$ ) had no values of predictor WRITING. This means that parameter $\beta 2$ represents the impact of talk about writing for parents who actually talked about the purpose of writing. 